\title{
Mandate to obtain consent for withholding nonbeneficial cardiopulmonary resuscitation is misguided
}

\author{
James Downar MDCM MHSc, Michael Warner MD MBA, Robert Sibbald MSc*
}

$\mathrm{T}$ he College of Physicians and Surgeons of Ontario recently revised their policy concerning decision-making at the end of life. ${ }^{1}$ The revised policy includes a new requirement for physicians to obtain consent to withhold cardiopulmonary resuscitation (CPR). Regardless of the medical situation, if a patient or substitute decision-maker does not agree with the decision to withhold CPR, then CPR must be provided in the event of cardiac arrest. Although intractable conflicts about end-of-life care are uncommon, this new requirement could have a broad and negative impact on end-of-life care in Ontario.

The new requirement was, in part, a response to a complaint filed with the college regarding the decision not to offer CPR to an elderly man with end-stage vascular disease whose condition was deteriorating after a bilateral above-knee amputation. The case was reviewed three times by the college. Twice, the college supported the actions of the physicians. The third review concluded that the physicians should have provided CPR, because they had not obtained agreement from the substitute decision-maker for a no-CPR order. There was no clear rationale provided for overturning the previous decisions and requiring the agreement of the substitute decision-maker to withhold CPR. In fact, recent case law has upheld the role of medical judgment when deciding whether or not to offer CPR. Ontario judges have been asked twice to provide an interim judgment to oblige physicians to provide CPR in the event of cardiac arrest. In both cases, the judges refused, making it clear that physicians should use their own judgment. ${ }^{2,3}$ However, the college's revised policy argues that the law is "unclear regarding consent requirements for a no-CPR order." 1

The requirement for consent to withhold CPR represents a double standard, because CPR is not always medically indicated, ${ }^{4}$ and consent legislation does not provide for any treatment to be given by default. Cardiopulmonary resuscitation may be performed when appropriate under emergency consent (according to Ontario's Health Care Consent Act); however, in patients with terminal illness, lack of a pulse is no more an absolute indication for CPR than malignant bowel obstruction is an absolute indication for surgery. It is illogical that physicians in a situation of disagreement may withhold nonbeneficial hemodialysis from a patient with multiorgan failure, but are required to perform CPR in the event of a hyperkalemic cardiac arrest. In patients admitted to hospital, CPR is a bridge to life support; if life support is determined to be inappropriate, CPR is not clinically indicated.

Cardiopulmonary resuscitation should be treated like every other medical treatment, as in the policies of the Canadian Medical Association, ${ }^{5}$ the British Medical Association, ${ }^{6}$ the Australian Medical Association, ${ }^{7}$ and a recent international policy statement from the Critical Care Society. ${ }^{8}$ The College of Physicians and Surgeons of Ontario justified the requirement for consent by stating that a unilateral no-CPR order would not respect patient autonomy, but they failed to explain why this rationale would not apply to decisions to withhold other medical treatments. They invite further confusion and conflict by stating that "physicians must act in good faith and use their professional judgment to determine how long to continue providing CPR." ${ }^{1}$ But what is the appropriate duration of inappropriate CPR? Continuing inappropriate CPR for any amount of time would be an act of poor judgment and bad faith, and may not even avoid conflict with the substitute decision-maker who insisted on its provision. Instead of filing a complaint that $\mathrm{CPR}$ was inappropriately withheld, the substitute decisionmaker could state that CPR was inappropriately stopped. How would the physician respond? If a physician's judgment cannot be trusted to determine when to withhold CPR, why would it be sufficient to determine when to stop CPR?
Competing interests: None declared.

This article has been peer reviewed.

Correspondence to: James Downar, james.downar@utoronto.ca

CMAJ 2016. DOI:10.1503 /cmaj.151205 
Although the stated goal of the college's policy was to encourage communication and conflict resolution, the policy is unlikely to do either. Communication gaps around end-of-life care have been well-documented, ${ }^{8}$ and the college could have simply reinforced a professional obligation to communicate and participate in conflict resolution as appropriate, regardless of the CPR order. Clearly, the college hopes the requirement for consent to withhold CPR will drive physicians to seek out conflict resolution pathways, including local hospital bioethics services and the Consent and Capacity Board. But the college received a submission from many hospital-based bioethicists who opposed the requirement for consent during the consultation process. And in the two years since the Rasouli decision from the Supreme Court of Canada (which required consent to withdraw lifesustaining measures, but did not address withholding them), ${ }^{9}$ the board has been consulted for only three end-of-life cases, compared with 24 cases in the four years before the decision. ${ }^{10}$ The Rasouli decision did not lead to more conflict resolution; it led to conflict avoidance and the provision of more aggressive life-sustaining therapy, even in cases to which the decision did not apply. ${ }^{11}$

The policy appears to encourage quality endof-life care, but it falls short in this regard as well. The college "advised" members about the merits of "integrating palliative care into the treatment plan as early as possible", ${ }^{1}$ but stopped short of using "require" or "must" for any palliative treatment or pain and symptom management. According to the policy, the only specific treatment that physicians "must" provide to dying patients is CPR. Palliative care physicians suggested a recommendation to provide treatment to dying patients who are in distress even if their family members are attempting to refuse comfort medications, which was not added. The sections on palliative care contain little more than general observations about options.

The college cited strong support for the revised policy from an online public opinion poll conducted as part of the consultation process. The poll showed strong support for requiring consent for a no-CPR order, but it also suggested a poor understanding of what CPR involves and unrealistically optimistic expectations of its outcome. This should have been seen as a learning opportunity - a call for education and public engagement - rather than the basis of a policy. It is illogical to respond to a broad misunderstanding about CPR by adopting a policy that would seem to reinforce it.

If the college's mandate is to protect the public, the requirement to perform inappropriate CPR is a violation of that mandate. CPR pro- vided to a patient with terminal illness is ineffective and may cause suffering, and there is no evidence that inappropriately aggressive care provides reassurance to bereaved family members; on the contrary, it likely harms them. ${ }^{12}$

Rather than mandate inappropriate CPR, the college should have recognized the grim reality of aggressive life-sustaining therapy and created a policy that promotes communication and comfort care for dying patients. High-quality end-oflife care may be the college's stated goal, but this revised policy will not achieve it.

\section{References}

1. Planning for and Providing Quality End-of-Life Care. Toronto: The College of Physician and Surgeons of Ontario; 2015 [updated]. Available: www.cpso.on.ca/Policies-Publications/Policy/Planning -for-Providing-Quality-End-of-Life-Care (accessed 2015 Sept. 18).

2. Ceferelli v. Hamilton Health Sciences 413 (ONCA 2013).

3. Cheah et al. v. Sunnybrook Health Sciences Centre et al., 03-102/10, October 22, 2010 (Ont SCJ 2010).

4. Annas GJ. CPR: when the beat should stop. Hastings Cent Rep 1982;12:30-1.

5. CMA Policy: CMA Statement on life-saving and -sustaining interventions. Ottawa: Canadian Medical Association; 2013 [updated]. Available: http://policybase.cma.ca/dbtw-wpd/Policypdf/PD14-01. pdf (accessed 2015 Feb. 1).

6. Decisions relating to cardiopulmonary resuscitation. $3 \mathrm{rd}$ ed. London: The British Medical Association; 2014. Available: www.resus.org.uk/pages/DecisionsRelatingToCPR.pdf (accessed 2015 Jan. 15).

7. Position statement on end of life care and advance care planning 2014. Australian Medical Association; 2014. Available: https://ama .com.au/sites/default/files/documents/AMA_position_statement_on_ end_of_life_care_and_advance_care_planning_2014.pdf (accessed 2015 Jan. 18).

8. Bosslet GT, Pope TM, Rubenfeld GD, et al. An official ATS/ AACN/ACCP/ESICM/SCCM policy statement: responding to requests for potentially inappropriate treatments in intensive care units. Am J Respir Crit Care Med 2015;191:1318-30.

9. Downar J, Sibbald RW, Bailey TM, et al. Withholding and withdrawing treatment in Canada: implications of the Supreme Court of Canada's decision in the Rasouli case. CMAJ 2014; 186:E622-6.

10. End of life cases. The Healthcare Consent Quality Collaborative; 2015 [updated]. Available: http://consentqi.ca/law/overview-2/ end-of-life-cases/ (accessed 2015 Nov. 13).

11. Cape D, Fox-Robichaud A, Turgeon AF, et al. The impact of the Rasouli decision: a survey of Canadian intensivists. J Med Ethics. In press.

12. Wright AA, Zhang B, Ray A, et al. Associations between end-oflife discussions, patient mental health, medical care near death, and caregiver bereavement adjustment. JAMA 2008;300:1665-73.

*On behalf of the Canadian Critical Care Society, the Canadian Society of Palliative Care Physicians, the Canadian Hospice Palliative Care Association, the Ontario Medical Association's Sections on Critical Care and Palliative Care, Dr. Bojan Paunovic, Dr. Gordon Rubenfeld and Dr. Cameron Guest.

Affiliations: Critical Care and Palliative Care, University Health Network, and Department of Medicine (Downar), University of Toronto; Critical Care Medicine, Toronto East General Hospital, and Department of Medicine, University of Toronto, and Critical Care Medicine, Ontario Medical Association (Warner), Toronto, Ont.; London Health Sciences Centre (Sibbald), London, Ont.

Contributors: James Downar, Michael Warner and Robert Sibbald contributed to the conception, drafting and revision of the manuscript, gave their final approval of the version to be published and agreed to act as guarantors of the work. The authorship group contributed to the revision of the initial draft and gave final approval of the version to be published. 